\title{
Effect of small-sided games with manipulation of small targets on the perceived exertion and tactical and technical performance of college soccer players
}

\section{Efeito de jogos reduzidos com manipulação de pequenos alvos sobre a percepção de esforco e o desempenho tático e técnico de jogadores de futebol universitário}

Deborah Touguinhó Gonet ${ }^{1}$

(D) https://orcid.org/0000-0002-7809-8541

Lucas Ometto Bezerra ${ }^{1}$

(D) https://orcid.org/0000-0003-1586-5587

Marcos Antônio Mattos dos Reis²

(D) https://orcid.org/0000-0003-2647-5859

Fabrício Vieira do Amaral Vasconcellos

(D) https://orcid.org/0000-0002-4522-4425

Abstract - The purpose of this study was to compare the tactical and technical performance and perceived exertion of college soccer players in small-sided games through the manipulation of small targets. Twenty players divided into four teams, played $5 \times 5$ games $(25 \times 20 \mathrm{~m})$ with one and two small targets on different days. Games were divided into three four-minute times, with two-minute intervals between bouts. Perceived exertion and technical-tactical variables were evaluated using Ball Transmission Speed (ball received/ball contacts) and Team Sport Assessment Procedure (TSAP). TSAP generates performance indicators, such as: efficiency index, performance score, volume of play and ball attack. They are related to the actions of balls conquered, passes and finalizations. For statistical analysis, paired t test and Cohen's d effect size were performed to compare the two game configurations. Larger number of balls conquered with small target was verified $(\mathrm{p}<0.05 ; \mathrm{d}=1.32)$, generating higher efficiency index and performance score. It was concluded that the perceived exertion is similar with one and two small targets and players recover more balls with only one small target. Through this information, coaches can better handle this type of constraints according to the purpose of the training session.

Key words: Athletic performance; Physical education and training; Soccer.

Resumo - O objetivo do estudo foi comparar o desempenho tático, técnico e a percepção subjetiva de esforço de jogadores de futebol universitário em jogos reduzidos através da manipulação de pequenos alvos. Vinte jogadores, divididos em quatro times, realizaram jogos de $5 \times 5$ (espaço:25x20 m) com um e com dois pequenos alvos, em diferentes dias. Os jogos foram divididos em três tempos de quatro minutos, com dois minutos de intervalo entre os tempos. Foi avaliada a percepção de esforço e variáveis técnico-táticas, utilizando a Velocidade de Transmissão da Bola (bolas recebidas/contatos na bola) e o Procedimento de Avaliação do Esporte em Equipe (TSAP). O TSAP gera indicadores de desempenho, como: indice de eficiência, escore de performance, volume de jogo e ataque com bola. Eles estão relacionados às açôes de bolas conquistadas, passes e finalizaçôes. Para análise estatística foi realizado teste tpareado e o taman ho do efeito d de Cohen para comparar as duas configuraçôes de jogo. Foi verificada uma maior quantidade de bolas conquistadas com um pequeno alvo ( $p<0,05 ; d=1,32)$, gerando maior indice de eficiência e escore de performance. Conclui-se que a percep̧̧ão de esforço é a mesma com um ou dois pequenos alvos e que um pequeno alvo faz com que os jogadores recuperem mais bolas. Através dessas informaçôes o treinador pode manipular melhor este tipo de constrangimento de acordo com o objetivo da sua sessão de treino.

Palavras-chave: Educação física e treinamento; Futebol; Performance esportiva.
1. State University of Rio de Janeiro. Laboratory of Soccer Studies. Graduate Program in Exercise and Sport Sciences. Rio de Janeiro - RJ. Brazil.

2. "Estácio" University Center of Sergipe. Aracaju, SE. Brazil.

Received: 30 June 2018 Accepted: 27 February 2019

How to cite this article Gonet DT, Bezerra LO, Reis MAM, Vasconcellos FVA. Effect of small-sided games with manipulation of small targets on the perceived exertion and tactical and technical performance of college soccer players. Rev Bras Cineantropom Desempenho Hum 2020, 22:e57958. DOI: http://dx.doi.org/10.1590/19800037.2020v22e57958

Copyright: This work is licensed under a Creative Commons Attribution 4.0 International License. 


\section{INTRODUCTION}

The practice of sports in the Brazilian university context has grown in recent years. Thus, the sports training process with emphasis on college soccer should gain more prominence, showing concern on the part of the sports sciences. For this reason, literature already reports some studies on this subject, highlighting the need to understand the effects of soccer training with this specific population. Studies conducted with college soccer have focused on issues related to the incidence of injuries ${ }^{1}$, biomechanical ${ }^{2}$, anthropometric ${ }^{3}$, physiological ${ }^{4}$ aspects and in particular small-sided and conditioned games (JRCs), as these have been the subject of study due to their wide use $\mathrm{e}^{5-7}$.

JRCs are small-sided games that aim to develop tactical, technical and physical skills in a perspective that comes close to the reality of the game ${ }^{8,9}$. With regard to studies with college soccer players, the study by Vilar et al. ${ }^{6}$ aimed at examining the effects of numerical superiority in JRCs on maintaining ball possession, number of goal shots and teammate passes. The authors compared three game configurations: $5 \times 5,5 \times 4$ and $5 \times 3$, verifying that players exhibit different behaviors and positions when compared to conditions of equality and numerical superiority or inferiority.

Despite the great advance in literature regarding the production of knowledge about JRCs, few studies have attempted to verify the effects of manipulating the amount of targets, even though it is a tool widely used by coaches. In a recent systematic review of constraints in small-sided and conditioned games, Ometto et al. ${ }^{10}$ found 24 studies where only five sought to analyze target manipulation in JRCs. The results found pointed to effects on tactical, technical and positional behavior of players. The review also showed that increasing the number of targets also increases the distance between teams, the time played along the side of the field and the number of finishes. When the size of targets increases, players become closer to each other and finish more often, unlike smaller targets, where ball possession maintenance stands out.

However, of the five studies found in this review, only the study by Castellano et al. ${ }^{7}$ sought to verify the effects of target manipulation on the performance of college soccer players. The authors analyzed the influence of the use of small targets, regular goalposts with goalkeepers and the presence of jokers on the positional behavior in a $4 \times 4$ small-sided game. The results found suggest that players adapt their collective behavior in the offensive and defensive phase according to the manipulation performed by the coach. Although the study used target manipulation in college soccer, the authors only addressed the tactical aspect, giving up other important demands of the soccer game, such as technical and physiological aspects.

Given the scarcity of studies on the subject, the increasing number of competitions and consequently training sessions in the university environment, and the need for soccer to be more fully analyzed, the aim of the present study was to compare the perceived exertion and tactical and 
technical performance of college soccer players in small-sized soccer games by manipulating small targets. It has been hypothesized that the use of two targets makes defensive organization difficult, presenting worse technicaltactical index, and that players work harder with this game configuration in view of the need to protect and attack two targets.

\section{METHOD}

\section{Sample}

The research project was approved by the Research Ethics Committee with protocol number 5259/2016. Twenty players from the male university soccer team of the State University of Rio de Janeiro participated in the study. All participants signed the Informed Consent Form (ICF) and responded to an anamnesis. The following inclusion criteria were adopted: training in the university team for at least two months; and as exclusion criterion: being injured in the month prior to data collection.

Players averaged $21.28 \pm 1.56$ years of age and body mass index (BMI) of $23.84 \pm 2.92 \mathrm{~kg} / \mathrm{m}^{2}$. The average time of soccer practice was $13.39 \pm$ 3.22 years. For experience time, the period from the first year of soccer practice to the year of data collection was considered.

\section{Instruments}

\section{- Evaluation of subjective perceived exertion}

At the end of each game, players individually answered a paper scale, which they were already familiar with, to obtain the Subjective Perceived Exertion (SPE) of the Borg CR-10 scale ${ }^{11}$.

\section{- Video Analysis}

All games were recorded with a Sony HDR CX220 camcorder, positioned towards the corner, located above the playing field at height enough to include all players and playing space, as observed in Figure 1. After recording, games were transferred to a Samsung AtivBook 2 notebook (Samsung Electronics Co., South Korea), where they were watched using Windows Media Player software (Microsoft Corporation, USA) and analyzed by two trained evaluators.

\section{- Tactical-Technical Performance Analysis - TSAP (Team Sport Assessment Procedure)}

To analyze the technical-tactical performance, two trained evaluators used the Team Sport Assessment Procedure (TSAP) ${ }^{12}$, described in Box 1. This tool proposes that through video analysis, the observer counts conquered balls (CB), received balls (RB), lost balls (LB), neutral passes (N), offensive passes $(\mathrm{OP})$ and successful shots (SS).

Then, technical-tactical performance indexes were calculated according to evaluation proposed in TSAP ${ }^{12}$. To calculate the Number of Attack Balls (NAB), Offensive Passes (OP) and Successful Shots (SS) were summed: 

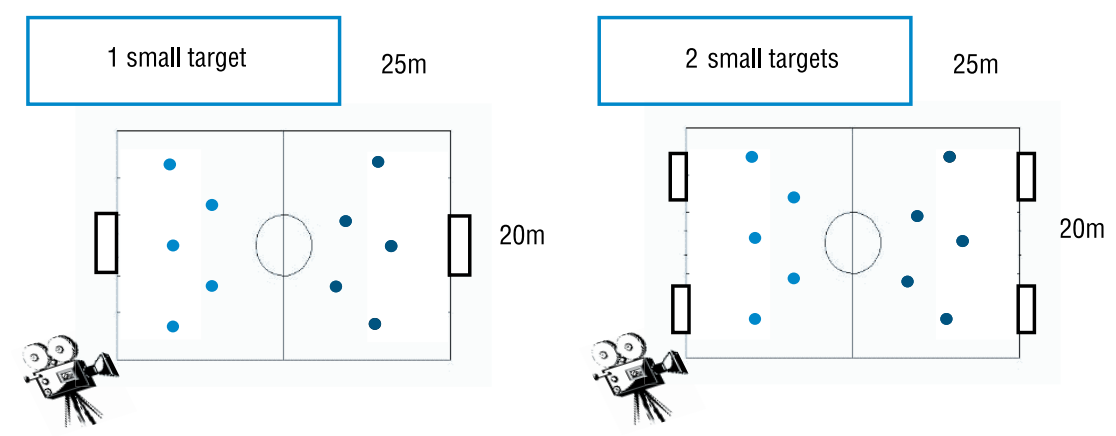

Figure 1. Illustrative image of the organization of games analyzed.

$\mathrm{NAB}=\mathrm{OP}+\mathrm{SS}$. From the results found, two indexes are obtained: Volume of play (VP), which is the sum of the number of received balls $(\mathrm{RB})$ and the number of conquered balls $(\mathrm{CB}): \mathrm{VP}=\mathrm{RB}+\mathrm{CB}$ and the Efficiency Index $(\mathrm{EI})$, where $\mathrm{EI}=(\mathrm{CB}+\mathrm{NAB}) /(10+\mathrm{LB})$. With the above indexes, we can achieve the Performance Score through the formula: (efficiency index x 10) + (volume of play / 2).

\section{- Tactical-Technical Performance Analysis - Ball Transmission Speed (BTS)}

Ball transmission speed is given by the number of received balls (RB) divided by the number of ball contacts $(\mathrm{BC})$ by the player analyzed ${ }^{13}$. Thus, BTS is an index from 0 to 1 , in which the ball transmission speed is higher the closer to 1 the obtained index. The analysis was performed by the same evaluators who performed the other analyses: BTS $=\mathrm{RB} / \mathrm{BC}$.

Box 1. Description of definitions assigned to each concept analyzed through TSAP'2.

\begin{tabular}{|ll|}
\hline Conquered Balls (CB) & $\begin{array}{l}\text { Resulting from an opposing pass interception, ball retrieve, } \\
\text { ball possession recovery after unsuccessful finishing of the } \\
\text { opponent or offensive rebound. }\end{array}$ \\
\hline Received Balls (RB) & $\begin{array}{l}\text { Receive a pass from a teammate and be able to maintain ball } \\
\text { control. }\end{array}$ \\
Lost Balls (LB) & $\begin{array}{l}\text { The player loses the ball, which becomes possession of the } \\
\text { other team. }\end{array}$ \\
Neutral Passes (N) & Pass that does not pose chance of successful shots. \\
Offensive Passes (OP) & Pass that generates the possibility of finishing. \\
Successful shots (SS) & When it is a goal or the ball is retrieved by the finishing team. \\
\hline
\end{tabular}

\section{Procedures}

Teams were divided by the coaching staff based on the subjective analysis of the quality of players, so that there was no technical imbalance. Four teams (A, B, C and D) of five players were formed. Matches were decided at random. In order to minimize possible result changes due to the influence of different opponents, team A played only against team B and team $\mathrm{C}$ against team $\mathrm{D}$. Each team played two matches, one with one small target and one with two small targets. The field had dimensions of $20 \times 25 \mathrm{~m}$ and the targets of $1.2 \times 0.6 \mathrm{~m}$. Matches were held two days apart, on the first 
day only games with one small target and on the second day, games with two small targets. Matches consisted of 3 times of 4 minutes, totaling 12 minutes, with 2 minutes of rest between each time. The official soccer rules were followed, except for the offside rule.

\section{Statistical analysis}

The reliability of records was performed by analyzing inter and intra-rater agreement by duplicate analysis of $\sim 10 \%$ of the total actions performed by players, and reanalyzed actions were defined by draw. The analysis was performed by the Kappa index and showed high degree of agreement between the two observations $(\mathrm{K}=0.85 ; \mathrm{K}=0.92 ; \mathrm{p}<0.001)$.

To verify data normality, the Kolmogorov-Smirnov test was performed, in which all data were normally distributed. For this reason, descriptive statistics using means and standard deviation of variables was adopted. To compare the averages of games performed with the condition of one small target and two small targets, the T-test for paired samples was performed, followed by Cohen's d-Test to determine the effect size. Effect size was considered as: insignificant effect $(\mathrm{d}<0.19)$, small effect $(0.20<\mathrm{d}<0.49)$, medium effect $(0.50<\mathrm{d}<0.79)$, large effect $(0.80<\mathrm{d}<1.29)$ and very large effect $(\mathrm{d}>1.30)^{14}$. The statistical analysis software used was SPSS 24.0 and the significance level used in all tests was $\mathrm{p} \leq 0.05$.

\section{RESULTS}

\section{Subjective perceived exertion}

Figure 2 shows the comparison between the playing condition with one small target and two small targets. No significant differences were found regarding perceived exertion.

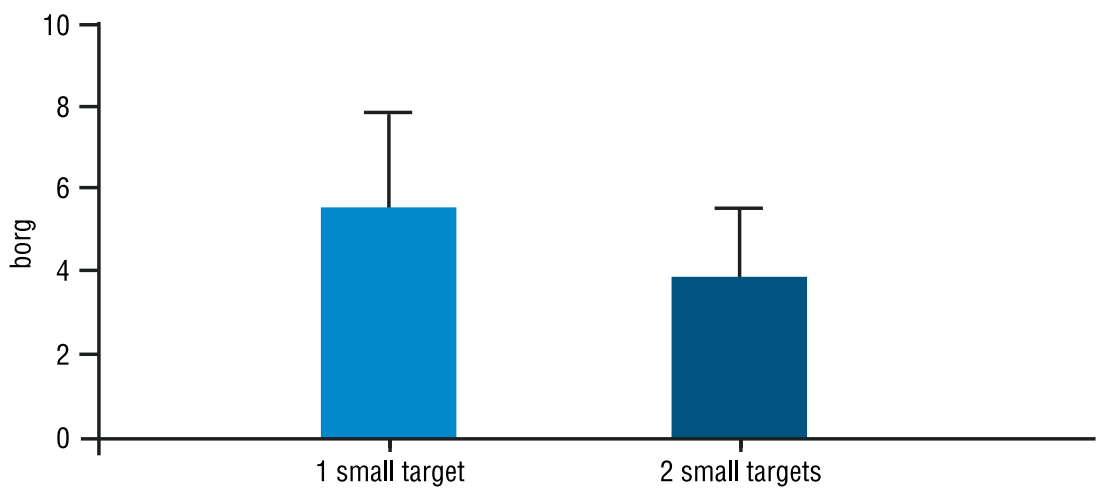

Figure 2. Comparison of the mean subjective perceived exertion.

\section{Technical-Tactical Performance}

Figure 3 shows that some technical-tactical variables were influenced by the manipulation of small targets. As shown in figure 3-a, in game with one small target, there was greater number of wrong passes $(d=1.54$; very large effect) and in figure $3-\mathrm{c}$, more balls were missed $(\mathrm{d}=2.25$; very large 
effect) and more balls were conquered $(\mathrm{d}=1.32$; very large effect).

Figure 4 shows that there was no difference in ball transmission speed (BTS) between games with one and two small targets. Figure 5 shows the technical-tactical indexes extracted from TSAP. Figure 5-c shows significant difference in the efficiency index $(\mathrm{d}=2.38$; very large effect $)$ and Figure 5-d shows higher performance score in game with one small target $(\mathrm{d}=2.18$; very large effect).
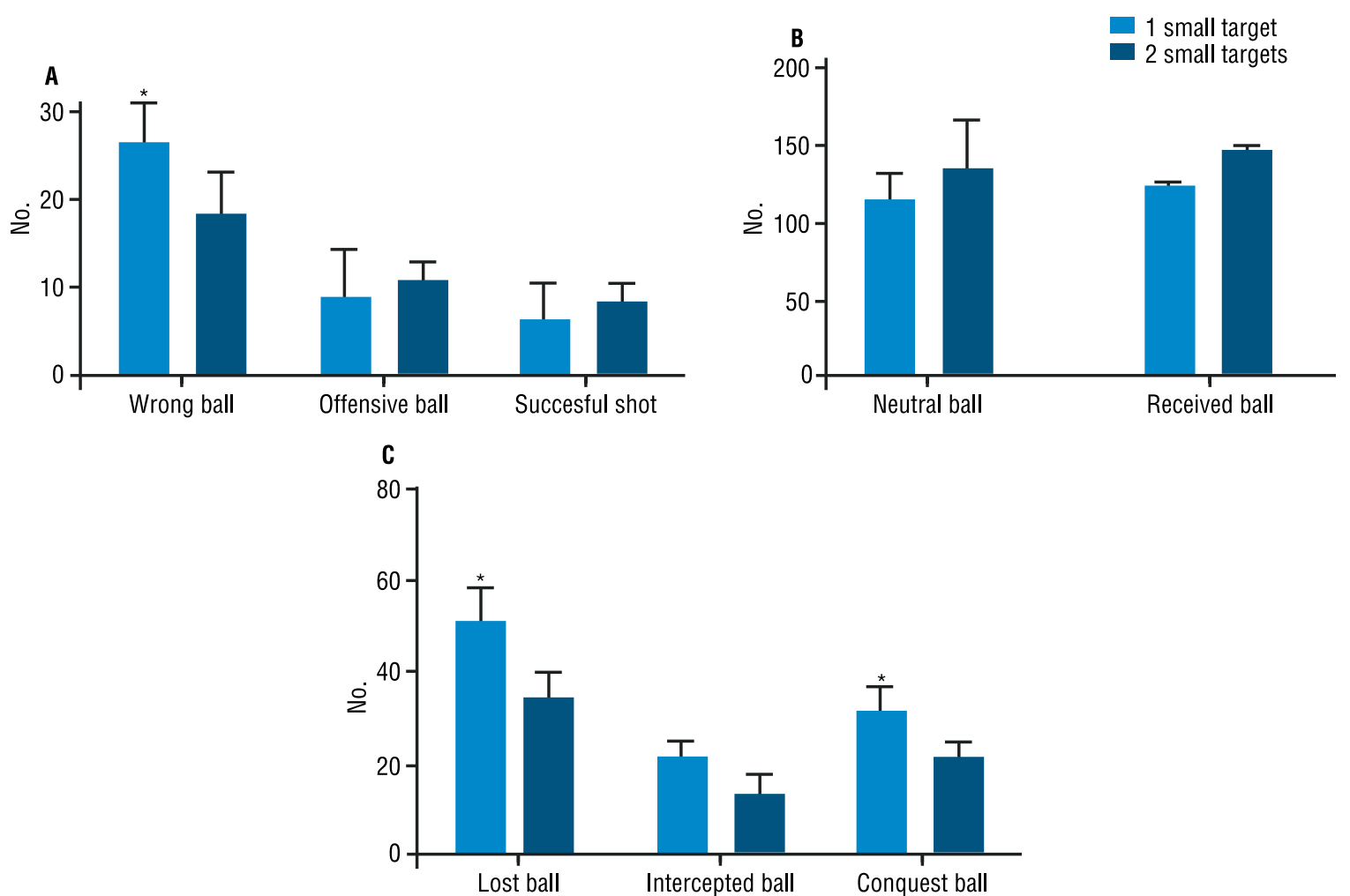

Figure 3. Comparison of technical-tactical components in one-or two-target games. 3a-Average amount of wrong ball, offensive ball and, successful shot. $3 b$ - Average amount of neutral ball and received ball. $3 c$ - Average amount of lost, intercepted and conquered ball. * Significant difference between groups $(p<0.05)$.

BTS

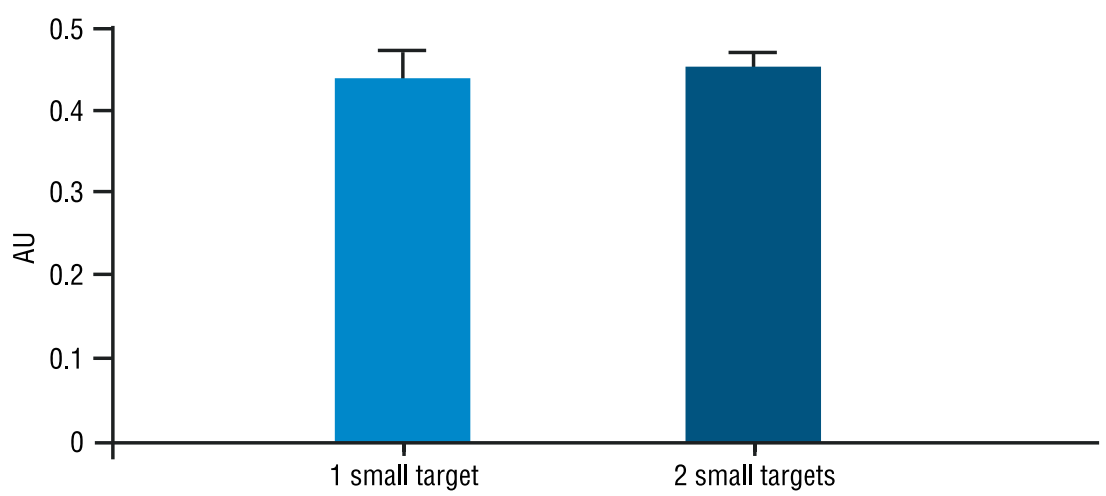

Figure 4. Comparison of the average ball transmission speed between games with one and two small targets. BTS: Ball Transmission Speed.

\section{DISCUSSION}

The present study aimed to compare the physical and technical-tactical 

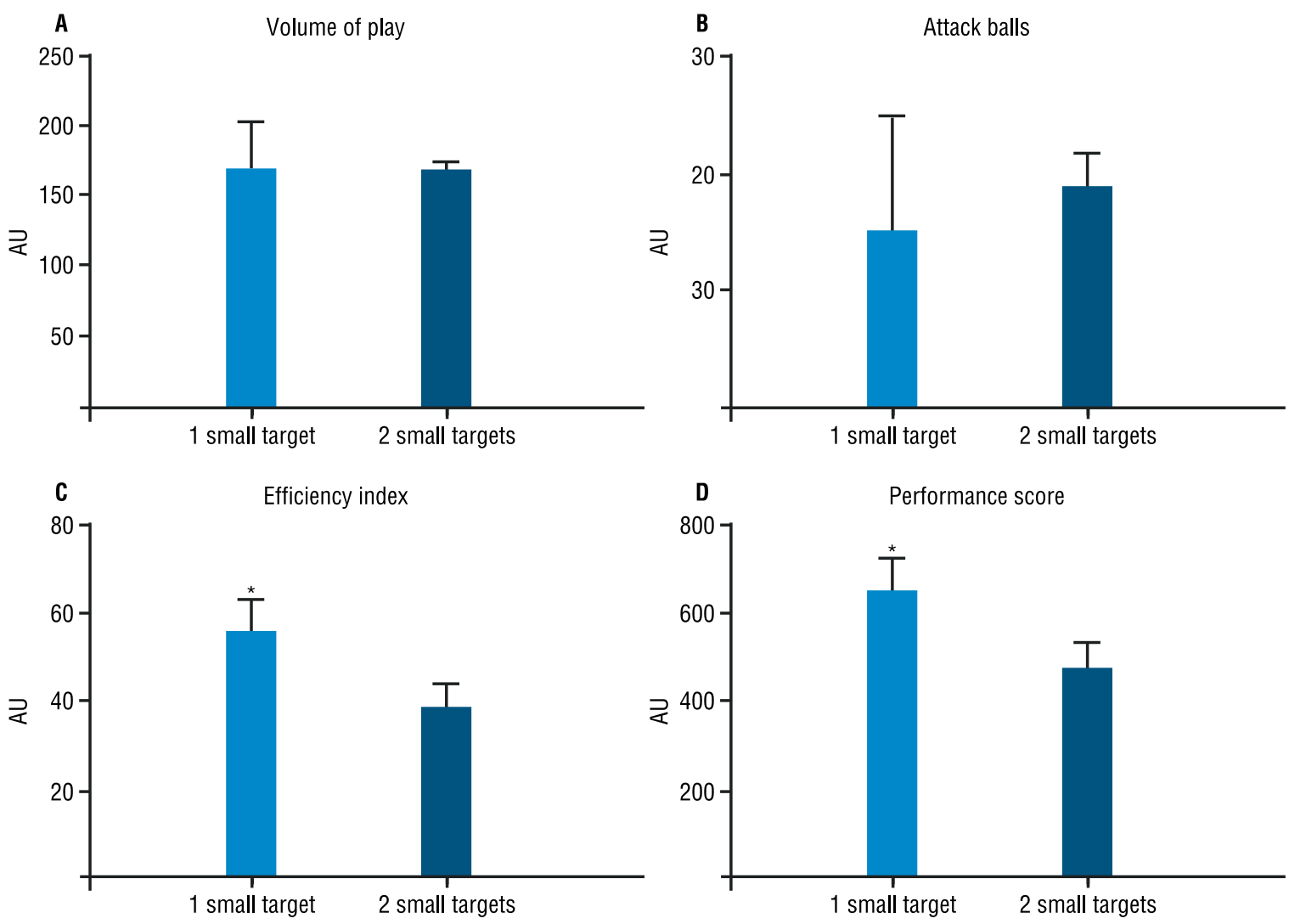

Figure 5. Comparison of technical-tactical indexes in games with one and two small targets. A, Volume of play. B, Attack balls. C, Efficiency index. D, Performance score. * Significant difference between groups $(p<0.05)$.

performance of college soccer players in small-sized games with one and two small targets. The main physical performance results showed that the perceived exertion was the same in both game configurations. Regarding the technical-tactical performance, with one small target, players made more wrong passes and had more ball possession, and presented higher efficiency index and performance score.

Regarding perceived exertion, the present study shows results similar to previous studies, since no significant differences in SPE were found in games with small targets. Using the 6-20 Borg scale ${ }^{11}$, Brandes et al. ${ }^{15}$ found no differences between one- and two-target game configurations. Halouani et al. ${ }^{16}$ sought to compare SPE in small-sized games with one small target and with scoring zone, and found no differences between game configurations. Thus, through the results found, the unique manipulation of the number of targets in reduced games does not seem to interfere with players' $\mathrm{SPE}^{15,16}$, which can be explained by the fact that the relative area occupied by each player has not been changed from one game to another.

The evaluation of the tactical-technical performance showed that with one small target, the occurrences of wrong passes, lost balls and conquered balls increased. These results corroborate those obtained in the study by Clemente et al. ${ }^{17}$ and Almeida et al. ${ }^{18}$, who observed that with one small target, players organize better defensively, leading to failure in passing and greater ball possession conquest. The results of the present study can be 
explained by the players' behavior of focusing more on the central portion of the field to protect the small target ${ }^{17,18}$ and in the closer proximity between teams ${ }^{19}$, thus reducing playing spaces. Thus, there is more difficulty in performing passes, causing more balls to be lost and the opposing team to conquer more balls.

Only two studies ${ }^{15,17}$ verified the technical-tactical performance in small-sized games through the Team Sport Assessment Procedure (TSAP). The results found by Clemente et al. ${ }^{17}$ indicate that there was no difference between investigated scoring methods. However, the study by Brandes et al. ${ }^{15}$ pointed to a higher volume of play in game with one small target when compared to two small targets. The present results are in disagreement with these results, since it found higher performance score and efficiency index in game with only one small target, thus confirming one of the hypotheses of the present study. These findings may have been influenced by the number of lost balls, because when the ball possession is lost by a team, it means that it is taken by the opposing team. Thus, the number of conquered balls, which directly influences the evaluated indexes, was higher when players aimed at protecting only one target, which facilitates greater defensive organization.

Surveys that analyzed BTS have focused on official games ${ }^{20,21}$, making the comparison with the present results difficult. Although no difference was found between small-sided games analyzed, when comparing the average BTS found in the formal game literature $(0.34 \pm 0.15 ; 0.39 \pm 0.02$ and $0.39 \pm 0.15$ ) and the present findings (one target: $0.44 \pm 0.03$ and two targets: $0.45 \pm 0.01$ ), higher ball transmission speed was observed in small-sided games. Higher BTS values may be related to the proximity of the opposing team, as the playing space is reduced and players need to pass the ball faster so that they do not lose ball possession.

\section{CONCLUSIONS}

In this sense, it could be pointed out that college soccer players have the same perceived exertion in games with one and two small targets. At the same time as the number of wrong passes, lost and conquered balls tend to be higher, the performance score and efficiency index appear to be better in games with one small target. Through the results of this study, it is believed that the manipulation of targets directly influences the technical-tactical variables. Thus, through this information, coaches can better handle this constraint, not only to modify the stimulus offered to athletes, but also to use this manipulation according to the purpose of the training session.

The sample size and the physical performance analysis based only on the perceived exertion can be pointed as limitations of the present study. However, it is noteworthy that due to the few studies conducted with this population, such limitations do not diminish the study importance. Despite the findings presented, it is evident that further research is needed on the subject, exploring different technical levels and other quantities / loca- 
tions of small targets, in addition to more robust research involving more thorough analysis of the physiological and technical-tactical performance of players in different small-sized game configurations.

\section{COMPLIANCE WITH ETHICAL STANDARDS}

\section{Funding}

This research did not receive any specific grant from funding agencies in the public, commercial, or non-profit sectors. This study was funded by the authors.

\section{Ethical approval}

Ethical approval was obtained from the local Human Research Ethics Committee - Rio de Janeiro University and the protocol (no. 52519815.4.0000.5259) was written in accordance with standards set by the Declaration of Helsinki.

\section{Conflict of interest statement}

The authors have no conflict of interests to declare.

\section{Author Contributions}

Conceived and designed the experiments: FVA and LO. Performed the experiments: LO and DT. Analyzed the data: DT and MAM. Contributed with reagents/materials/analysis tools: DT and LO. Wrote the paper: LO, DT, MAM and FVA.

\section{REFERENCES}

1. Goodman AD, Etzel C, Raducha JE, Owens BD. Shoulder and elbow injuries in soccer goalkeepers versus field players in the National Collegiate Athletic Association, 2009-2010 through 2013-2014. Phys Sportsmed 2018;46(3):304-311.

2. Orloff H, Sumida B, Chow J, Habibi L, Fujino A, Kramer B. Ground reaction forces and kinematics of plant leg position during instep kicking in male and female collegiate soccer players. Sports Biomech 2008;7(2):238-247.

3. Peart AN, Nicks CR, Mangum M, Tyo BM. Evaluation of Seasonal Changes in Fitness, Anthropometrics, and Body Composition in Collegiate Division Ii Female Soccer Players. J Strength Cond Res 2018;32(7):2010-2017.

4. Sharma SK, Raza S, Moiz JA, et al. Postactivation Potentiation Following Acute Bouts of Plyometric versus Heavy-Resistance Exercise in Collegiate Soccer Players. Biomed Res Int 2018;2018:1-8.

5. Aguiar M, Botelho G, Lago C, Maças V, Sampaio J. A review on the effects of soccer small-sided games. J Hum Kinet 2012;33:103-113.

6. Vilar L, Esteves PT, Travassos B, Passos P, Lago-Peñas C, Davids K. Varying numbers of players in small-sided soccer games modifies action opportunities during training. Int J Sports Sci Coach 2014;9(5):1007-1018.

7. Castellano J, Silva P, Usabiaga O, Barreira D. The influence of scoring targets and outer-floaters on attacking and defending team dispersion, shape and creation of space during small-sided soccer games. J Hum Kinet 2016;51(1):153-163.

8. Casarin RV, Reverdito RS, de Lima Greboggy D, Afonso CA, Scaglia AJ. Modelo de jogo e processo de ensino no futebol: princípios globais e específicos. Movimento 2011;17(3):133-152. 
9. Práxedes A, Moreno A, Gil-Arias A, Claver F, Del Villar F. The effect of smallsided games with different levels of opposition on the tactical behaviour of young footballers with different levels of sport expertise. PloS One 2018;13(1):e0190157.

10. Ometto L, Vasconcellos FVA, Cunha FA, et al. How manipulating task constraints in small-sided and conditioned games shapes emergence of individual and collective tactical behaviours in football: A systematic review. Int J Sports Sci Coach 2018;0(0):1-15.

11. Borg G. Borg's perceived exertion and pain scales. Human kinetics; 1998.

12. Gréhaigne J-F, Godbout P, Bouthier D. Performance assessment in team sports. J Teach Phys Educ 1997;16(4):500-516.

13. Dugrand M. Football, de la transparence à la complexité. Presses universitaires de France; 1989.

14. Rosenthal JA. Qualitative descriptors of strength of association and effect size. J Soc Serv Res 1996;21(4):37-59.

15. Brandes M, Müller L, Heitmann A. Physiological responses, time-motion characteristics and game performance in 4 vs. 4 small-sided games in elite youth soccer players: different number of mini-goals vs. stop-ball. Sci Med Foot 2017;2(1):1-6.

16. Halouani J, Chtourou H, Dellal A, Chaouachi A, Chamari K. Physiological responses according to rules changes during 3 vs. 3 small-sided games in youth soccer players: stop-ball vs. small-goals rules. J Sports Sci 2014;32(15):1485-1490.

17. Clemente FM, Wong DP, Martins FML, Mendes RS. Acute effects of the number of players and scoring method on physiological, physical, and technical performance in small-sided soccer games. Res Sports Med 2014;22(4):380-397.

18. Almeida CH, Duarte R, Volossovitch A, Ferreira AP. Scoring mode and age-related effects on youth soccer teams' defensive performance during small-sided games. J Sports Sci 2016;34(14):1355-1362.

19. Travassos B, Gonçalves B, Marcelino R, Monteiro R, Sampaio J. How perceiving additional targets modifies teams' tactical behavior during football small-sided games. Hum Mov Sci 2014;38:241-250.

20. Moraes EL, Cardoso F, Teoldo I. Análise dos padrões ofensivos da Seleção Espanhola de Futebol na Copa do Mundo FIFA ${ }^{\circledR} 2010$ em relação ao" status" da partida. Rev Bras Educ Fís Esp 2014;28(3):361-369.

21. Santos R, Moraes E, Teoldo I. O status da partida ea amplitude de circulação da bola da seleção espanhola de futebol na Copa do Mundo Fifa ${ }^{\circledR}$ 2010. Rev Bras Ciênc Esporte 2016;38(4):358-362.

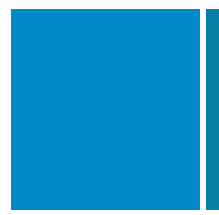

Corresponding author

Fabrício Vieira do Amaral Vasconcellos

524 São Francisco Xavier St, Rio de Janeiro, RJ

5521, BRA

CEP: 20550-013 - tel.: 5521 2234-0775

Email: fabriciovav@gmail.com 